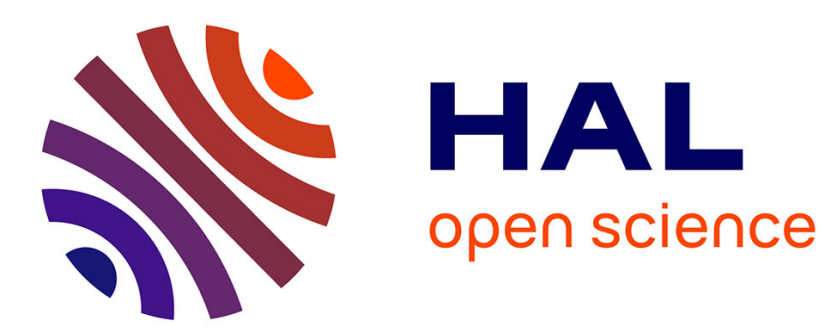

\title{
FOCUSED DROPLET BEAM FROM A GOLD LIQUID METAL ION SOURCE
}

\author{
Gérard Benassayag, Jean Orloff, L. Swanson
}

\section{To cite this version:}

Gérard Benassayag, Jean Orloff, L. Swanson. FOCUSED DROPLET BEAM FROM A GOLD LIQUID METAL ION SOURCE. Journal de Physique Colloques, 1986, 47 (C7), pp.C7-389-C7-397. 10.1051/jphyscol:1986766 . jpa-00225961

\section{HAL Id: jpa-00225961 https://hal.science/jpa-00225961}

Submitted on 1 Jan 1986

HAL is a multi-disciplinary open access archive for the deposit and dissemination of scientific research documents, whether they are published or not. The documents may come from teaching and research institutions in France or abroad, or from public or private research centers.
L'archive ouverte pluridisciplinaire HAL, est destinée au dépôt et à la diffusion de documents scientifiques de niveau recherche, publiés ou non, émanant des établissements d'enseignement et de recherche français ou étrangers, des laboratoires publics ou privés. 
JOURNAL DE PHYSIQUE

Colloque C7, supplément au $\mathrm{n}^{\circ} 11$, Tome 47, Novembre 1986

FOCUSED DROPLET BEAM FROM A GOLD LIQUID METAL ION SOURCE

\author{
G. BENASSAYAG, J. ORLOFF* and I.W. SWANSON* \\ Laboratoire de Microstructures et de Microélectronique, \\ 196. Avenue Henri Ravera, F-92220 Bagneux, France \\ - Oregon Graduate Center, 19600 Von Neumann Dr, Beavorton. \\ OR 97006, U.S.A.
}

\begin{abstract}
A gold LMIS has been used in the charged droplet emission mode with a single lens focusing column operating at $20 \mathrm{kV}$ beam voltage to achieve a deposit size at the target of 2.3 to $6.0 \mathrm{\mu m}$ depending on the exposure time. The net mass deposit rate maximized at $1.5 \mathrm{\mu m}^{3} / \mathrm{s}$. From the focusing characteristics an energy spread of $50 \mathrm{~V}$ and an energy deficit of 350 to $500 \mathrm{~V}$ could be inferred for the charged droplet beam.
\end{abstract}

\title{
I INTRODUCTION
}

Liquid metal ion sources (LMIS) provide a high brightness ion beam which is ideally suited for fine focus applications such as scanning microscopy, ion microlithography, micromachining and high resolution SIMS. Singly and doubly-charged ions, charged molecular clusters and droplets are present in the beam to varying degrees as a function of total emission current.

originally, the charged droplet emission mode vas studied as a possible source for electric space propulsion [1], hovever, the lower current ion emission mode soon dominated the research interests. Nevertheless possible applications for large area [2] and localized [3] metal film deposition has caused a small but continued interest in the droplet emission mode. Mahony and Prewett [3] used a focused gold droplet beam at an emission current $I=600 \mu \mathrm{A}$ to obtain a $300 \mu \mathrm{m}$ vide focused beam of droplets. Recently D'Cruz et. al.[4] investigated various properties of the emission characteristics of the droplet emission mode of a gold LMIS. They gave an estimation of the droplet virtual source size of $8 \mu \mathrm{m}$ along with other emission characteristics and obtained gold films with fine texture morphology. An important conclusion of their work was that the droplet emission occurred from the apex of the elongated Taylor cone.

In this work, we examine the properties of both unfocused and focused beams of charged droplets from a Gold LMIS. The current dependence of the droplet size and the corresponding droplet emission rate were determined. From the focused beam results the energy deficit and broadening of the droplet beam could be estimated. 


\section{EXPERIMENTAL METHOD}

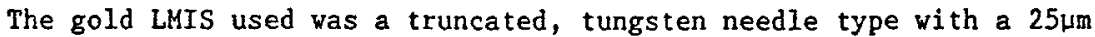
radius flat ground on top of a $90^{\circ}$ cone. The needle was spot welded to a tungsten wire spiral containing the gold reservoir which allowed flow onto the shank of the needle. When a high positive voltage, greater than the threshold value, is applied to the needle the liquid meniscus forms a cone-like shape and the well known ion emission occurs at a few $\mu$ a of current. This current can be varied widely from 1 to several hundred $\mu \mathrm{A}$. At low current the beam consists mainly of Aut and Au+t, but with increasing current other species such as neutral atoms, charged molecular clusters and droplets appear in the beam [5].

The droplet emission becomes important only for large current and a deposit occurs when the deposit rate exceeds the ion sputtering rate. Because the LMIS current is usually limited by the liquid metal supply, the use of a large needle radius to enhance the flow rate to the emitter apex has been suggested [3]. The particular source shape used in this investigation provided a stable and long life droplet source.

A single, electrostatic lens column, shown in Fig. 1, was used to focus the droplets. During operation the vacuum level of the column was maintained at $1 \times 10^{-7}$ torr using $200 \mathrm{l} / \mathrm{s}$ vac-ion pumping system. Combined beam deflection and astigmatism correction was carried out with an octupole

stigmator/deflector. The optical properties of the asymmetric lens have been determined elsewhere [6]. For this study a beam acceptance half angle of 2.0 $\operatorname{mr}$ (140 yA diameter aperture) was used. The large emitter radius required a relatively high extraction voltage of 15 to $20 \mathrm{kV}$ for the indicated geometry; for this study the first element of the lens was grounded, thereby allowing the more convenient einzel operating mode to be used.

In addition to the focused beam investigation, a simple diode deposition study similar to $D^{\prime}$ Cruz, et. al. [4] was carried out. In this study the gold LMIS was positioned $1 \mathrm{~mm}$ from a flat silicon (111) wafer and the gold deposit examined by SEM.

\section{EXPERIMENTAL RESULTS}

\section{A. Diode Results}

The first studies of the droplet emission were performed in the closespaced diode system. After operating the gold LMIS for $120 \mathrm{~s}$ at a current of $150 \mathrm{\mu A}$ the silicon target was examined in an SEM. Fig. 2 shows an SEM photo of the gold deposit on the silicon target which exhibits a $60 \mu \mathrm{m}$ diameter bright-centered gold deposit surrounded by a larger dark circle of sputtered silicon surface. Beyond this circle the brightness is due to the thermally deposited gold. In agreement with $\mathrm{D}^{\prime} \mathrm{Cruz}$, et. al, we found a $2^{\circ}$ droplet beam divergence in contrast to a $40^{\circ}$ divergence for the monomer ion beam.

Using a Sloan Dektak profilometer the volume deposit rate and angular flux were calculated to be $610 \mathrm{\mu m}^{3} / \mathrm{s}$ and $6.7 \times 10^{5} \mu^{3} / \mathrm{s} / \mathrm{sr}$ respectively. The latter is in excellent agreement with the value of $5 \times 10^{5} \mu^{3} / \mathrm{s} / \mathrm{sr}$ reported by $D^{\prime}$ Cruz, et. al. for a gold LMIS operating at $135 \mu \mathrm{A}$. As discussed below, assuming an average droplet size of $0.5 \mu \mathrm{m}$ one can calculate an average droplet emission rate of $-1 \mathrm{kHz}$, also in agreement with $D^{\prime}$ Cruz et. al. If one further assumes that on the average each particle carries a single charge, then one can calculate that within the $1^{\circ}$ acceptance half angle there is $\sim 10^{-2}$ charged particles per atom deposited in droplet form; thus, one would expect to eventually reach an equilibrium size of deposit where removal by sputtering and deposition are equal. 


\section{B. Focused Droplet Results}

In a preliminary experiment with the focusing column, the emitter was operated without any focusing in order to study the current dependence of the droplet size and flux. The beam acceptance was about $2 \mathrm{mr}$ and the source to silicon target distance was $18 \mathrm{~cm}$. The ion source was operated at different current levels from 100 to $300 \mu \mathrm{A}$ for $120 \mathrm{~s}$. From the SEM photographs of the droplet deposit on the target, we obtained a size distribution of the droplets as shown in Fig. 3. These results show that the droplet size is relatively uniform throughout the field of view and increases from a mean value of 0.25 to $1.75 \mu \mathrm{m}$ as the current increases from $100 \mu \mathrm{A}$ to $300 \mathrm{\mu A}$. The average number of droplets per unit area was surprisingly constant at a rate of $\sim 0.056$ droplets $/ \mu^{2} / \mathrm{s}$ and independent of emission current in the range investigated.

In the focusing experiments the scanning ion microscope image (formed by the secondary electrons) was used to focus the ion beam as perfectly as possible; next, droplet deposition on various target positions was performed as the beam was slowly underfocused and then overfocused. After examination of the target in the SEM we found that when the ion beam was focused the droplet beam was overfocused and that the best droplet focus for $150 \mu \mathrm{A}$ enission current was about $500 \mathrm{~V}$ (in terms of lens excitation) below the best ion focus. This result agrees with studies of the energy properties of gold clusters (up to $\mathrm{Au}^{5+}$ ) emitted from LMIS, which have an energy deficit, depending on the cluster size and charge, up to several hundred volts [5].

Next an attempt was made to measure the focused droplet deposition rate and deposit shape. SEM photographs in Fig. 4 show a typical gold deposit and its corresponding profile for a $120 \mathrm{~s}$ exposure time. The deposit shape had a roughly Gaussian profile and therefore could be characterized by a full width at half maximum (FWHM) and deposit thickness height (h). Table I summarizes the deposit characteristics as the exposure time vas varied from 10 to $120 \mathrm{~s}$.

Fig. 5 gives a graphical representation of the variation of deposit volume and ratio of h/FWHM with deposit time. Interestingly, the deposit volume does not increase linearly with time, but shows a short induction period, followed by a linear increase with time an then a sharp leveling off for $t>60 \mathrm{~s}$. Similarly, the droplet shape, after initially exhibiting a shallow deposit shape with a small value of $h / F W E M$, became more peaked as h/FWHM increased to a value of 9 and then remained constant with further exposure. The deposit rate maximized at $-1.5 \mu^{3} / \mathrm{s}$ at a 60 s exposure. As expected this value of deposit rate is smaller than the $610 \mu \mathrm{m}^{3} / \mathrm{s}$ rate for the unfocused case by the ratio of the solid angle of the apertured to unapertured beam (i.e. $\left.(.002 / .017)^{2}\right)$.

In another experiment we attempted to characterize the effect of the droplet energy spread on the deflected beam due to the transverse chromatic aberration effect. Fig. 6 shows a gold deposit on axis and at $0.5 \mathrm{~mm}$ distance from this axis. The off-axis deposit is clearly distorted along the deflection direction as expected. The deposit elongation ( $\Delta d)$ was obtained from profile SEM analysis of the Fig 6 deposits to roughly estimate the beam energy broadening $(\Delta V)$ by

$$
\Delta V / V=\Delta d / d
$$

where $d$ is the on axis beam size. $A$ value of $\Delta V=50 \mathrm{~V}$ was obtained for the energy spread of the charged droplet beam.

We were also able to make an estimate of the energy deficit of the droplet beam relative to the ion beam by noting the difference in deflection amplitude between the ion and droplet beams for fixed deflection 
and beam voltages. Accordingly, the relative energy deficit was estimated to be $350 \mathrm{~V}$ for the droplet beam at $150 \mathrm{\mu A}$ emission current. This is in reasonable agreement with the less accurate method of noting the change in focus voltage between the droplet and ion beams which gave a value of $\sim 500 \mathrm{~V}$ as mentioned earlier.

Fig. 7 demonstrates the ability to deflect the focused beam to form 100 $\mu m$ long deposited gold lines. The two lines of equal length were obtained by using sweep times of 70 and $140 \mathrm{~s}$ and an emission current of $150 \mu \mathrm{A}$. The width of the lines are 4 and $6.5 \mu \mathrm{m}$ respectively. Their morphology is very rough but. a profile view indicates that there is no discontinuity.

\section{DISCUSSION}

At $150 \mu \mathrm{A}$ of emission current droplet emission was of the order of 1 to $10 \mathrm{kHz}$ in agreement with the relaxation times associated with the formation of the Taylor cone as pointed out earlier by $D^{\prime}$ Cruz, et. al. The droplet emission occurs with a very high flux due to its stiall angular confinement. Although there is a range of droplet sizes, the average size increases from 0.5 to 2.0 $\mu \mathrm{m}$ with increasing current. Thus, a relatively large portion of the few nanometer sized Taylor cone apex is removed during droplet formation leading to total mass flow rates of $\sim 600$ to $1000 \mu \mathrm{m}^{3} / \mathrm{s}$. The details of the droplet formation mechanism are not completely clear at this time, but undoubtedly involve hydrodynamic instabilities in the liquid cone as the mass flow rate increases above a critical value. The somewhat larger energy deficits associated with the charged droplets suggest its formation occurs further out from the position where ions are formed. However, in view of the fact that the energy spread is quite narrow, of the same order as the monomer ions (50 to $100 \mathrm{~V}$ ) [7], the droplet formation occurs in a relatively small increment of distance from the emitter surface. For example, if the electric field is $\sim 2$ $V / \AA$ the droplet formation occurs within a $100 \AA$ region positioned 600 to $1000 \AA$ from the reference surface.

In view of the concomitant emission of both charged droplets and charged monomer ions simultaneous deposition and sputtering are occurring for both focused and non-focused beams. In fact because the ion flux is several orders of magnitude greater than the droplet flux and traveling at a much higher velocity, the droplets will be sputtered to some extent during flight. The results suggest that for both focused and nonfocused modes the deposit gradually forms into a particular equilibrium shape such that the sputtering and deposition rates are equal. The dependence of sputtering on angle of incidence probably determines the slope of the peaked deposit shape when steady state is achieved.

The focused beam size $d$ is limited by the chromatic aberration coefficient $C_{c o}$ of the lens and the energy spread of the droplets as follows:

$$
\mathrm{d}_{c}=\mathrm{MC} \mathrm{co}_{0} \alpha \Delta V / \mathrm{V}
$$

where $M$ is the overall magnification of the column. The values of $M$ and $C_{c o}$ are 2.67 and $187 \mathrm{~mm}$ respectively. Thus, for $\Delta V=50 \mathrm{~V}$ and $V=20 \mathrm{kV}$ one calculates a value of $d_{c}=2.5 \mu \mathrm{m}-a$ value that is in good agreement with the Table I results for the $10 \mathrm{~s}$ exposure deposit. From their studies, D'Cruz et. al. were able to conclude that the virtual source size ( $d_{v}$ ) of the droplet source was $<8 \mu \mathrm{m}$; from this investigation we can conclude that

$d_{v}<2.5 \mu \mathrm{m}$. Because of the surprisingly small energy spread of the droplet beam one can readily deflect the beam over small distances $(<0.5 \mathrm{~mm})$ wi thout appreciable beam broadening due to transverse chromatic aberration. With reduction of $\mathrm{C}_{\mathrm{C}}$ further reduction of the on axis beam size can be realized. 


\section{CONCLUSION}

The ability to focus the charged droplets emitted from a gold LMIS has been demonstrated. Despite the limit of chromatic aberration a focused beam size of $\sim 2.5 \mu \mathrm{m}$ with a mass flow rate of 1 to $1.5 \mathrm{\mu m}^{3} / \mathrm{s}$ has been demonstrated by a simple single lens colum. The use of this phenomena to provide means to pattern small areas with metal films is obvious. For example, a combination of droplet mode emission for mass deposition and submicron, focused monomer ion beam mode emission for micromachining and trimming of the deposit can be envisioned.

\section{ACKNOWLEDGMENTS}

This work was supported in part by National Science Foundation Grant No. ELS8303095 .

\section{TABLE I}

Deposit dimensions for focused beam results at $150 \mu \mathrm{A}$ emission current and $20.2 \mathrm{kV}$ beam voltage.

\begin{tabular}{cccc}
$\begin{array}{c}\text { Exposure } \\
\text { time }(s)\end{array}$ & $\begin{array}{c}\text { FWHM } \\
(\mu \mathrm{m})\end{array}$ & $\begin{array}{l}\text { Thickness } \\
(\mu \mathrm{m})\end{array}$ & $\begin{array}{l}\text { Meximum } \\
\text { Volume } \\
\left(\mu \mathrm{m}^{3}\right)\end{array}$ \\
\hline 10 & 2.3 & 0.27 & 1.62 \\
\hline 30 & 4.5 & 1.6 & 25.9 \\
\hline 60 & 5.8 & 2.4 & 92 \\
\hline 120 & 5.8 & 2.4 & 92 \\
\hline
\end{tabular}

\section{REFERENCES}

1. V.E. Krohn, Progress in Astro. and Rocketry, $\underline{5}$, (1961) 73.

2. P.D. Prewett, L. Gowland, K.L. Aitken and C.M. Mahony, Thin Solid Films 81, (1981) 117.

3. C.M. Mahony and P.D. Prewett, Vacuum 34, (1984) 301.

4. C. D'Cruz, K. Pourrezaei and A. Wagner, J. App1. Phys. 58, (1985) 2724.

5. P. Sudraud, C. Colliex and J. van de Walle, J. Physique Lett. 40, (1974) L207.

6. J. Orloff and L.W. Swanson, J. Appl. Phys. 50, (1979) 2494.

7. A.R. Waugh, J. Phys. D: Appl. Phys., 13, (1980) L203. 


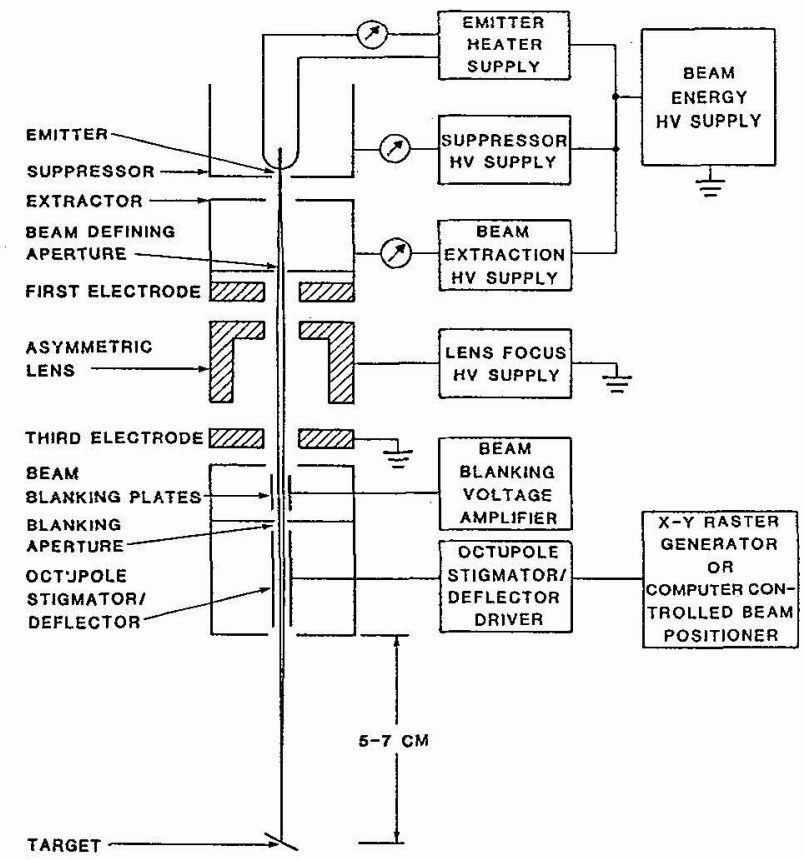

1. Diagram of the single lens focusing column. The suppressor electrode was removed for this study.

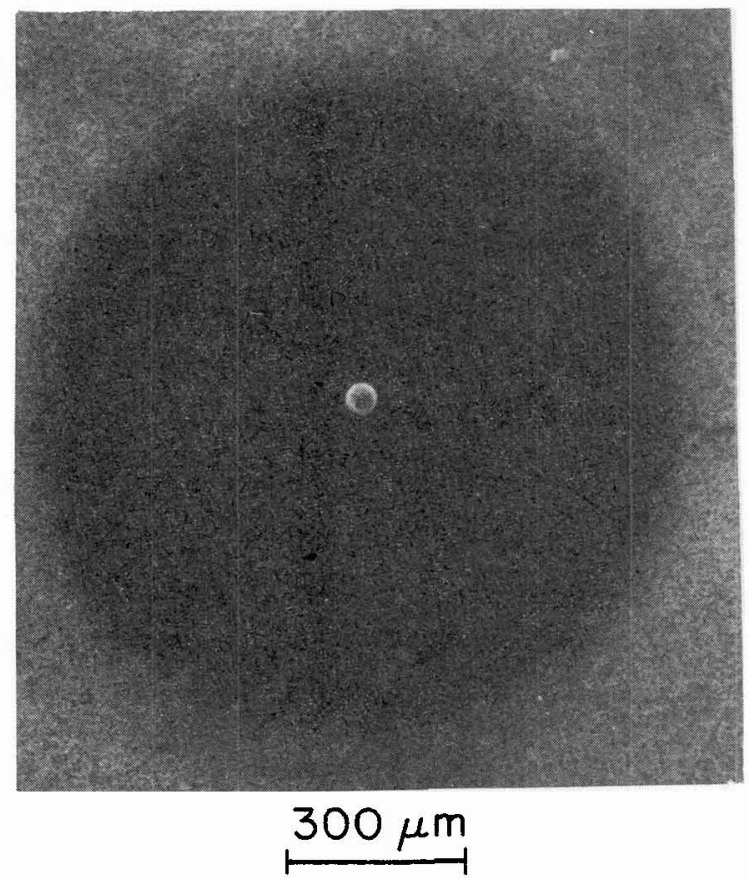

2. Gold LMIS deposit on a Si target placed $1 \mathrm{~mm}$ from the emitter. Emission current and exposure time were $150 \mu \mathrm{A}$ and $120 \mathrm{~s}$ respectively. 


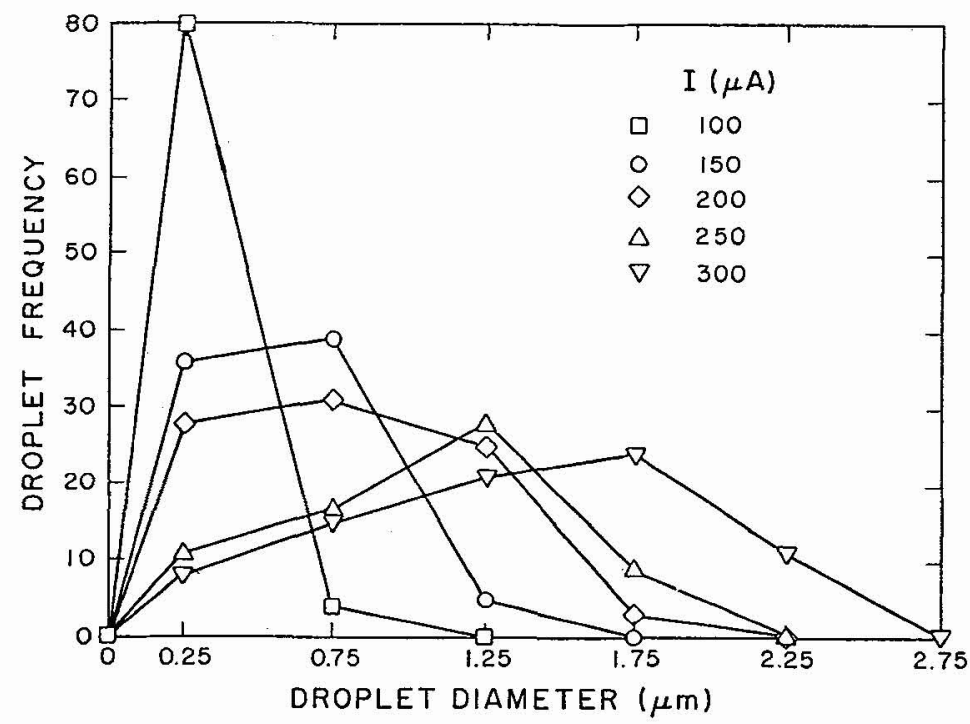

3. Distribution of droplet size for the indicated emission currents and $120 \mathrm{~s}$ exposure time. A target area of $520 \mu \mathrm{m}^{2}$ was examined and the droplet size increment was $0.5 \mu \mathrm{m}$.
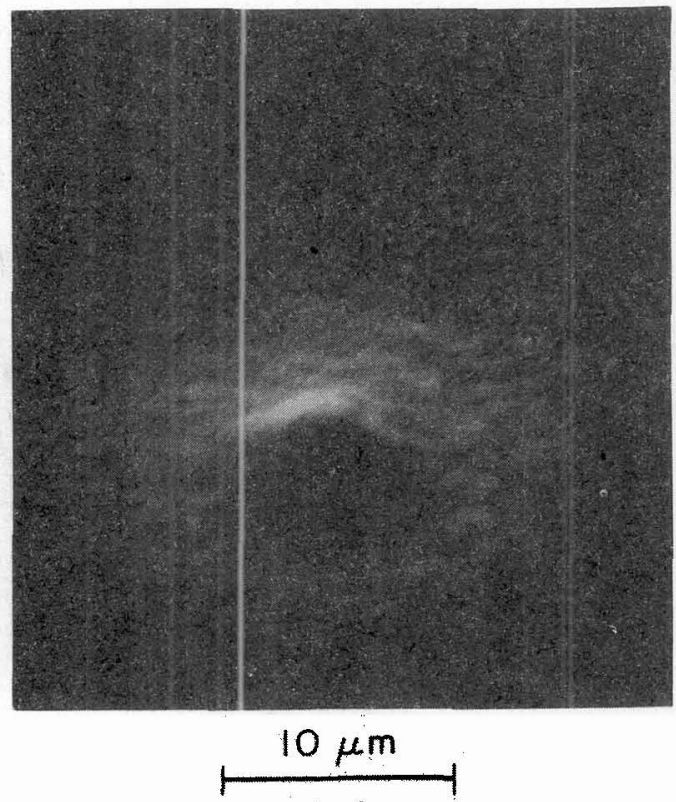

(a)
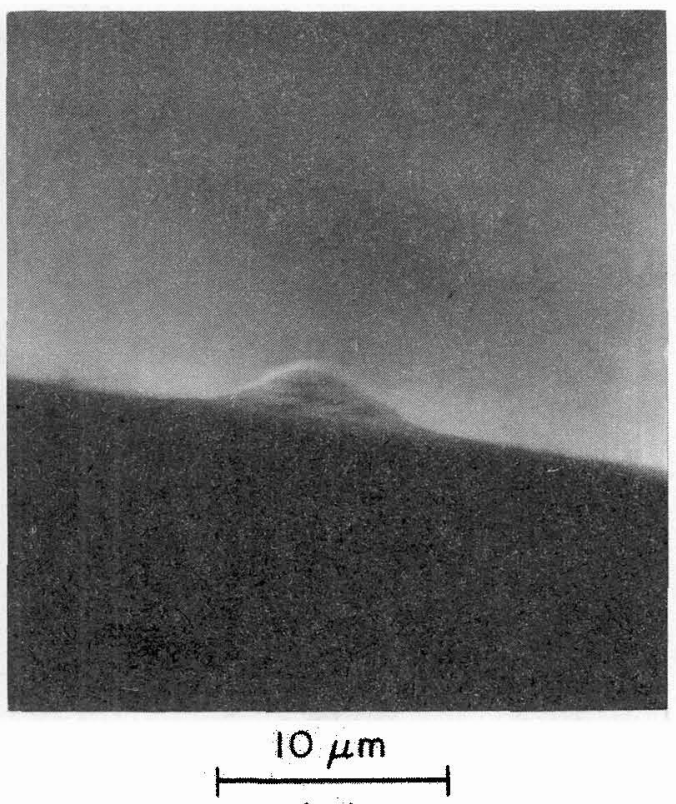

(b)

4. Typical shape of the focused beam deposit showing top (a) and side (b) views for a $60 \mathrm{~s}$ exposure at $150 \mu \mathrm{A}$ emission current and $20.2 \mathrm{kV}$ beam volt tage. 


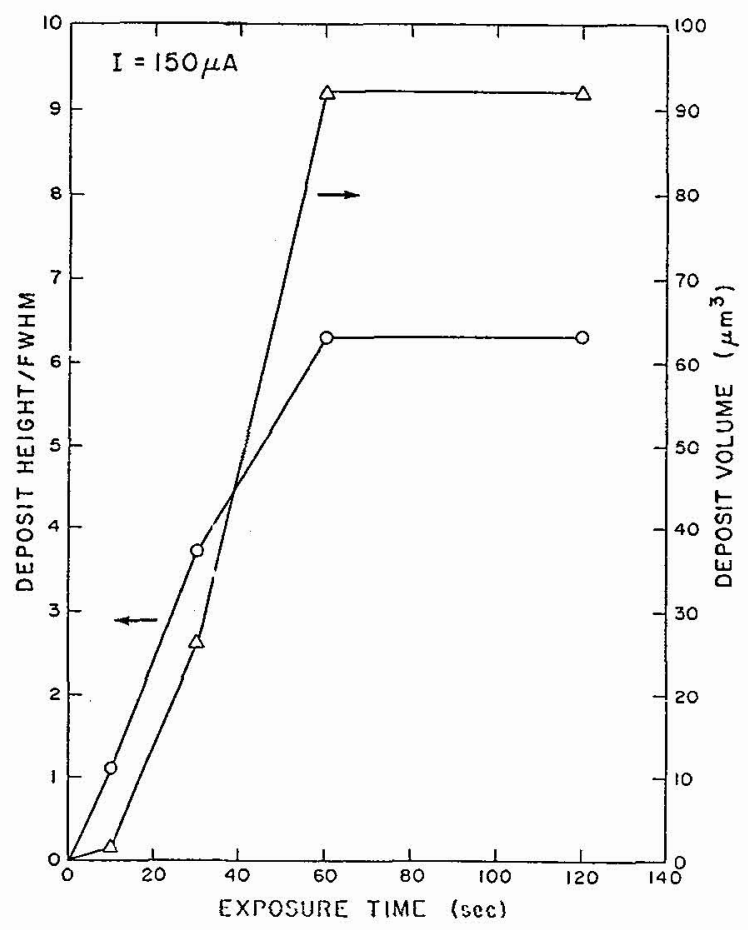

5. Plots of the ratio of the deposit height to width and deposit volume vs. time for a focused droplet beam at an emission current of $150 \mu \mathrm{A}$ and $20.2 \mathrm{kV}$ beam voltage.
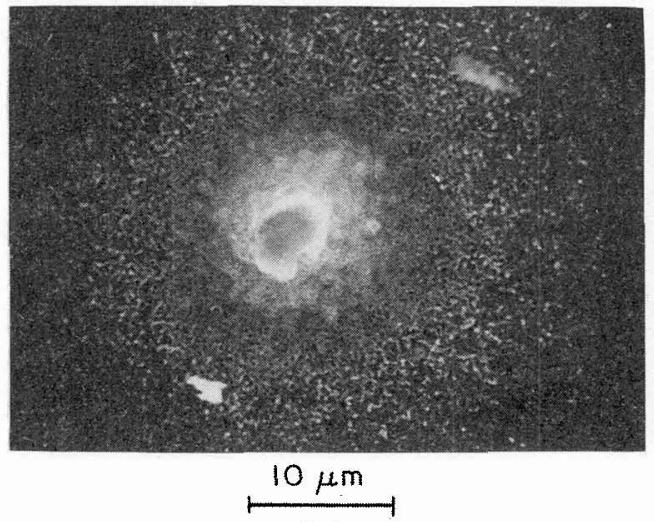

(a)

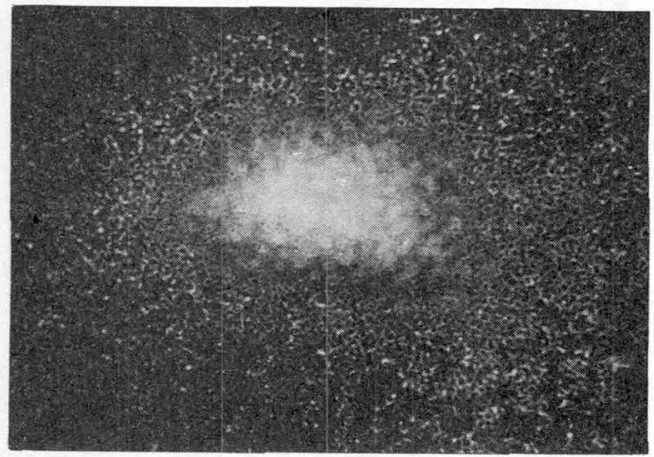

$\stackrel{10 \mu \mathrm{m}}{-}$

(b)

6. SEM photos of the focused beam deposit on axis (a) and deflected $0.5 \mathrm{~mm}$ off axis (b) for a $20.2 \mathrm{kV}$ beam voltage. The exposure time was $120 \mathrm{~s}$ and beam current was $150 \mu \mathrm{A}$. 

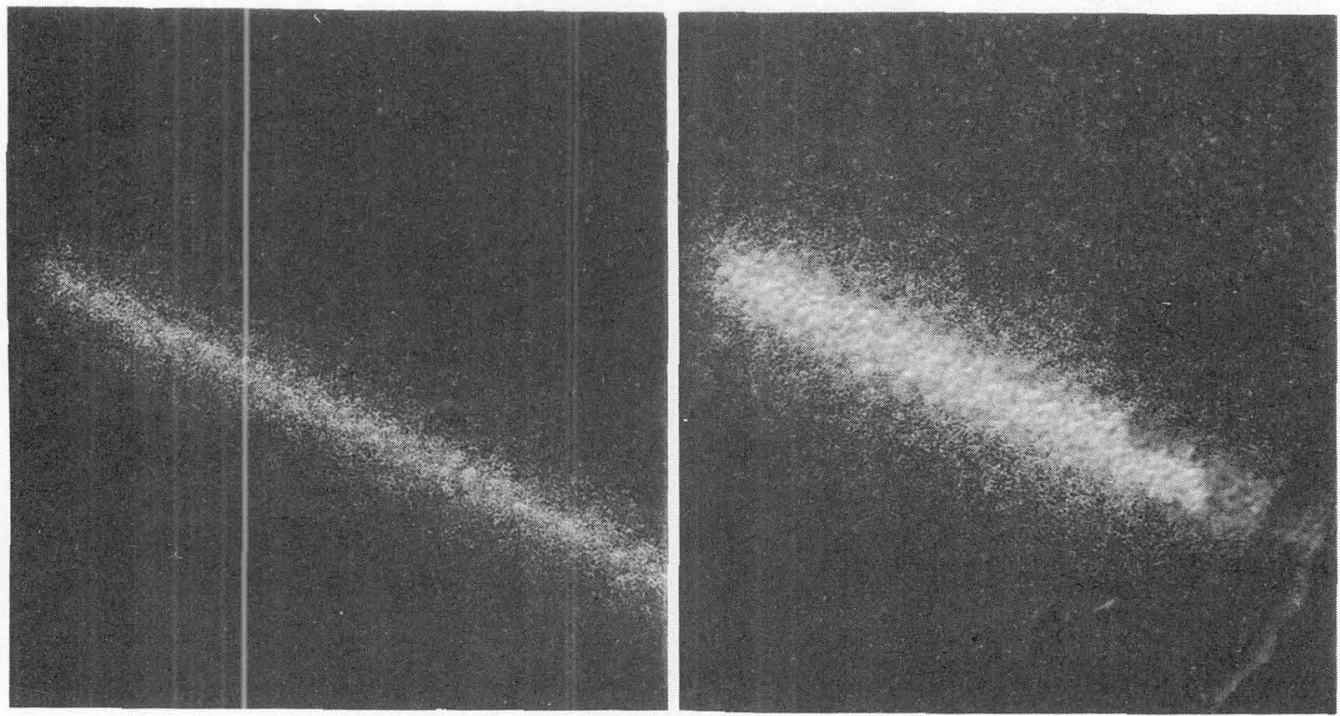

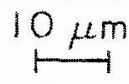

(a)

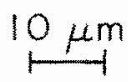

(b)

7. SEM photos of a line scan of the focused droplet beam for scan rates of 1.4 (a) and 0.71 (b) $\mu \mathrm{m} / \mathrm{s}$ at an emission current of $150 \mu \mathrm{A}$ and $20.2 \mathrm{kV}$ beam vol tage. 